Annals of Tropical Research 30[1]:60-71 (2008)

(c) VSU, Leyte, Philippines

\title{
Pollen morphology and viability of some Indian mangroves
}

\section{Suparna Gupta ${ }^{1}$, Arunima Ghosh ${ }^{1}$, Subrata Maity ${ }^{1}$ and Sauren Das ${ }^{2}$}

${ }^{1}$ Department of Seed Science and Technology, Bidhan Chandra Krishi

Viswavidyalaya, Mohanpur, Nadia - 741252, India; ${ }^{2}$ Agricultural and Ecological Research Unit, Indian Statistical Institute, 203 B.T. Road, Calcutta 700108, India

\begin{abstract}
A study on pollen morphology of four common Indian mangroves from Sundarbans mangrove swamps, three species from the family Rhizophoraceae (Bruguiera sexangula Laur., Ceriops tagal Perr.and Rhizophora mucronata Lamk.) and one species from the family Avicenniaceae (Avicennia marina Forsk.) was carried out. Shape of the pollen grains were prolate, prolate spheroidal and subprolate with tricolporate apertures. Surface ornamentation of the studied taxa was reticulate, finely reticulate or scabrate. Pollen grain viability of the said taxa was determined by stain test ( $1 \%$ aceto-orcein) under in situ condition and percentage of viable pollen production was recorded. The result revealed that all the studied taxa produce a fairly good amount of viable pollen grains in natural condition, an indication that they are good propagule producer in the long run. Pollen grain germination and measurements of pollen tube length using different sucrose concentrations $(0.2,0.6,1.0,1.2,1.6$ and $2.0 \%)$. Maximum pollen fertility and pollen tube length occurred in $2 \%$ sucrose solution in case of $A$. marina and $B$. sexangula, whereas $1.6 \%$ in C. tagal and $1.0 \%$ in R. mucronata. A strong positive correlation exist between pollen germination and pollen tube length, but there was a hardly relation between sucrose concentration and pollen tube length.
\end{abstract}

Keywords: mangroves, pollen morphology, pollen viability, pollen germination, pollen tube growth

Correspondence: S. Das. Address: Agricultural and Ecological Research Unit, Indian Statistical Institute, 203 B.T. Road, Calcutta 700108, India.E-mail: sauren@isical.ac.in DOI: $10.32945 /$ atr3015.2008 


\section{INTRODUCTION}

Mangrove plants (as distinct from mangrove communities or mangals) can be defined as tropical or subtropical ligneous plants that occur in intertidal and adjacent communities. Such plants exhibit various adaptations to cope with their hostile environment (Nandy (Data) et al. 2007). As the vast vegetational swamps are the natural transition between land and sea, in the tropical and sub-tropical estuarine ecosystem, mangrove vegetation plays a vital role in the proper maintenance of the coastal ecosystem. These habitats are affected by humidity, precipitation, saline substrates, and temperature. Plants are well adapted to the changing biological, chemical and physical traits of this environment through various xeromorphic properties, including morphology, anatomy and physiology (Waisel 1972; Zimmermann 1983; Das 1999). Being restricted to tropical coasts, ecological and socio-economic importance of mangroves is unquestionable. As 'energy traps' and 'nurse ecosystems', mangroves are the primary producers and reproductive zones which shelter and feed many offshore populations. Throughout the tropics, mangroves also have significant local economic importance as source of timber, firewood, pulp, honey and natural or manipulated fisheries. Mangrove ecosystems currently cover $146,530 \mathrm{~km}^{2}$ of the tropical shorelines of the world (FAO 2003). This represents a decline from 198,000 $\mathrm{km}^{2}$ of mangroves in 1980 , and $157,630 \mathrm{~km}^{2}$ in 1990 (FAO 2003). These losses represent about $2.0 \%$ per year within 1980-1990, and 0.7\% per year within 1990-2000.

In the Indo-Gangetic plain, Sundarbans forest forms one of the largest mangrove vegetations with a wide range of species diversity. In Indian Territory, the vegetation extends between $21^{\circ} 31^{\prime}$ to $21^{\circ} 31^{\prime} \mathrm{N}$ and $88^{\circ} 10^{\prime}$ to $89^{\circ} 51^{\prime}$ 'E. In western part (Indian territory) the forest area covers approximately 2,195 $\mathrm{km}^{2}$ (Sanyal 1996) excluding the anastomosing network of creeks and backwaters.

It is well known that successful fruit and seed setting depend largely on viable pollen grains. The 'floral construction' is defined as the syndrome of adaptive characters needed for pollen transfer that has evolved under phylogenetic developmental and environmental constraints (Claßen-Bockhoff 2007). Tyagi (2002) observed pollen viability in three species of the genus Rhizophoraceae and reported as very high $(>80 \%)$. 
Much has been reported on pollen grains of mangroves (Caratini et al. 1980; Thanikaimoni 1987; Das and Ghose 1990), but these were mainly on morphological and taxonomical aspects. In a successful cross, pollen viability plays a vital role in seed settings and as such, a reliable method of testing pollen viability is essential to determine the optimum time for pollination (Yang and Endo 2005). Studies on the relationship between viability and pollen germination reported a positive correlation between these variables (Warner and Chang 1981; Pearson and Harney 1984; Parfitt and Ganeshan 1989). Information on pollen viability of mangroves in natural condition is limited, hence, it is important to study it with respect to successful pollination and ultimately fruit production. The study of pollen viability along with pollen morphology of the investigated taxa may lead to an expression of the plants productivity in situ condition and ultimately to their fitness to the ecosystem. Viability could be measured by in vitro pollen germination techniques in different concentrations of sucrose solution $(0.2-2.0 \%)$ or, by stain test using $1 \%$ aceto-orcein. Stain tests have advantages as indicators of pollen viability, because they are faster and easier than pollen germination. But in some cases confusing results may be obtained in stain test. Therefore, to determine the actual amount of viable pollens, germination test is necessary. The hanging drop test has been used to determine the rate of pollen germination. Here the objectives of the present work are to study the viability, germination and pollen tube length of some mangrove taxa from Sundarbans and to determine the interrelationship, if any.

\section{MATERIALAND METHODS}

Materials were collected from mature flowers of well-identified three members of the family Rhizophoraceae (Bruguiera sexangula, Ceriops tagel and Rhizophora mucronata) and one member of the family Avicenniaceae (Avicennia marina) from the western part of the Sundarbans swamps (namely Namkhana, Patharpratima and Bakkhali of 24 Parganas (south) of West Bengal, India). This area is included under the "buffer" zone of the Sundarbans Tiger Reserve Forest Area (Fig. 1). Plants were selected due to their abundant growth in this area. 


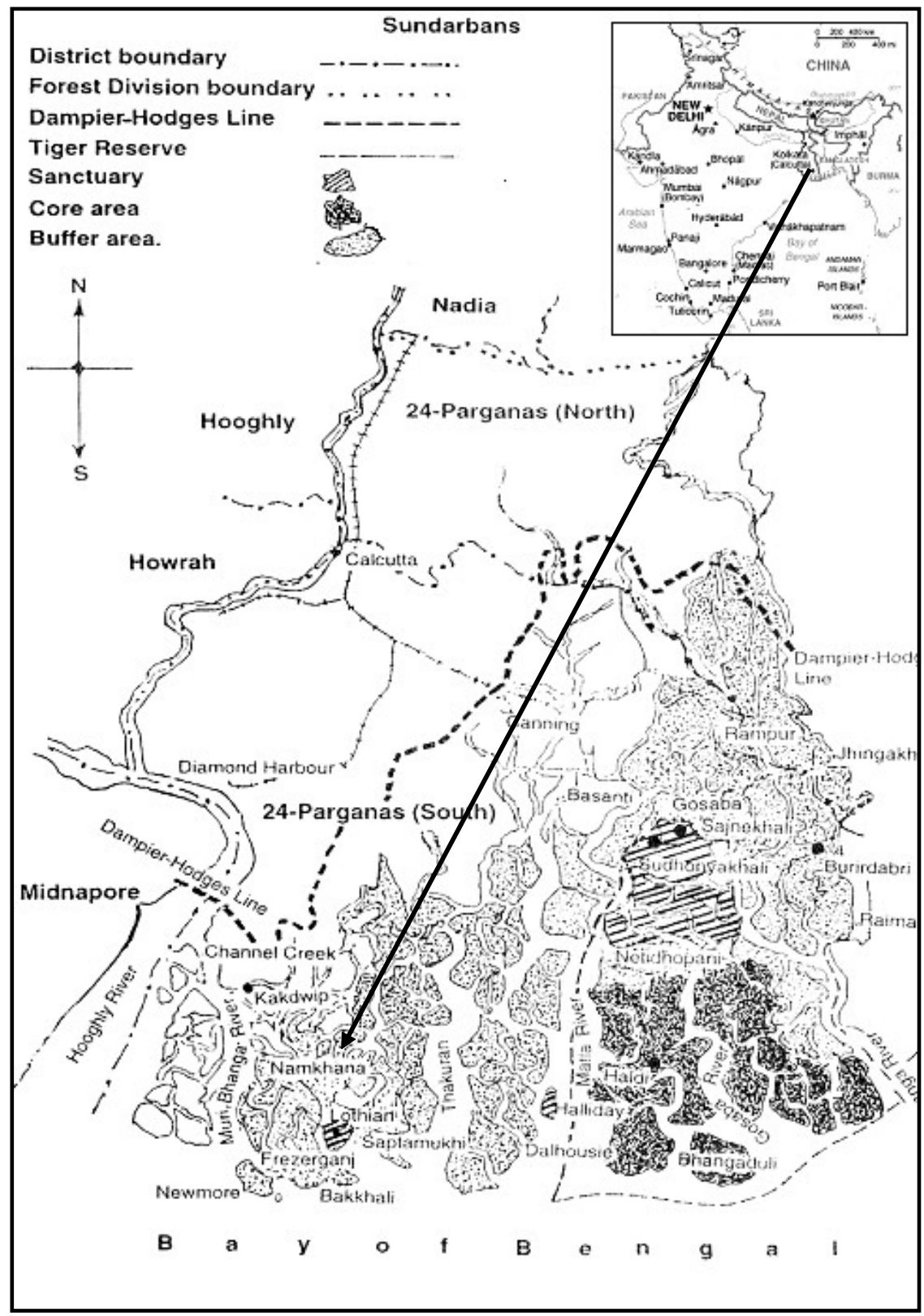

Fig. 1. Location map of the study area 
Pollen morphological study was carried out with fresh air dried pollen grains using usual acetolysis method (Faegri and Iversen 1975). Morphological parameters were observed and photomicrographs were taken with 10x and 20x objectives of the fluorescence microscope (Axiolab, Zeiss, MC 80 Dx Camera). Aceto-orcein test was adopted to determine the pollen viability (Muccifora et al. 2003). Fresh pollens were taken out and dusted over the slide and then stained with $1 \%$ aceto-orcein stain. Observations were made using ten slides and standard errors were calculated.

Six different sucrose concentrations $(0.2,0.6,1.0,1.2,1.6$ and $2.0 \%)$ were used in hanging drop test to determine in vitro pollen germination (Youmbi et al. 2004). One drop of each solution was placed on grooved slides separately. Freshly collected, uncontaminated pollens from newly dehisced anther were placed on the solution. The slides were kept in Petri dishes lined with moist filter paper. After 24 hours, the percentage of pollen germination and pollen tube elongation were observed under the microscope. The germination percentages were calculated and optimum sucrose concentration for germination was also recorded. Correlation between pollen fertility and

pollen tube length were calculated by SPSS version 12 and presented in Table 2.

\section{RESULTS}

\section{Pollen description of the investigated taxa}

Avicennia marina (Forsk.) Vierh. (Avicenniaceae) (Fig. 2A, B)

Pollen grains tricolporate, isopolar, radially symmetric, amb circular, peritreme, prolate, PA x ED $23.7+0.13 \times 18.7+0.08 \mu \mathrm{m}$. L/B of colpi 16.2 $+0.09 / 3.7+0.05 \mu \mathrm{m}$., ora circular, diameter of ora $3.1+0.02 \mu \mathrm{m}$., mesocolpium $5.0+0.08 \mu \mathrm{m}$., apocolpium $7.5+0.27 \mu \mathrm{m}$. Thickness of exine $3.7+0.11 \mu \mathrm{m}$., intectate, thickness of sexine $1.9+0.07 \mu \mathrm{m}$., reticulate, thickness of nexine $1.8+0.05 \mu \mathrm{m}$. 


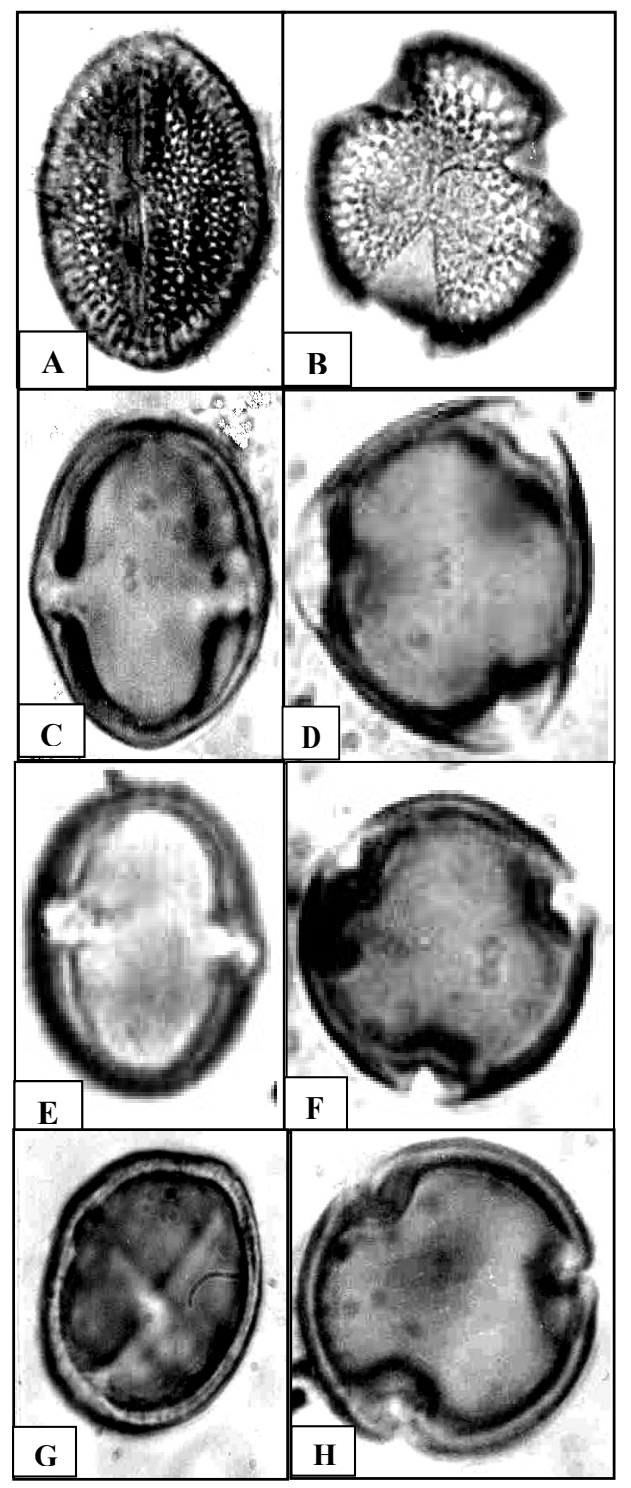

Fig. 2. A - H. Photomicrographs of the investigated pollen grains. A, B. Avicennia marina, A. equatorial view (x 750), B. polar view (x 750); C, D. Bruguiera sexangula, C. equatorial view (x 810), D. polar view (x 1050); E, F. Ceriops tagal, E. equatorial view (x 1000), F. polar view (x1175); G, H. Rhizophora mucronata, G. equatorial view (x 870), H. polar view (x 1230). 
Bruguiera sexangula (Laur.) poir. (Rhizophoraceae) (Fig. 2C, D)

Pollen grains tricolporate, isopolar, radially symmetric, amb circular, peritreme, prolate-spheroidal, PA x ED $15.4+0.12 \times 14.0+0.08 \mu \mathrm{m}$. L/B of colpi $7.0+0.03 / 2.1+0.13 \mu \mathrm{m}$., brevicolpate, ora lalongate, $\mathrm{L} / \mathrm{B}$ of ora $2.8+0.03 / 5.6+0.07 \mu \mathrm{m}$., mesocolpium $7.0+0.12 \mu \mathrm{m}$., apocolpium $4.9+$ $0.2 \mu \mathrm{m}$. Thickness of exine $1.4+0.06 \mu \mathrm{m}$., tectate, thickness of sexine $0.7+$ $0.02 \mu \mathrm{m}$., finely reticulate, thickness of nexine $0.7+0.03 \mu \mathrm{m}$.

Ceriops tagal (Perr.) Robins. (Rhizophoraceae) (Fig. 2E, F).

Pollen grains tricolporate, isopolar, radially symmetric, amb circular, peritreme, subprolate, PA x ED $16.2+0.13 \times 14.0+0.17 \mu \mathrm{m}$. L/B of colpi $11.2+0.07 / 1.8+0.08 \mu \mathrm{m}$., ora circular, diameter of pore $3.7+0.11 \mu \mathrm{m}$., mesocolpium $7.5+0.2 \mu \mathrm{m}$., apocolpium $6.2+0.16 \mu \mathrm{m}$. Thickness of exine $2.5+0.16 \mu \mathrm{m}$., tectate, thickness of sexine $1.8+0.22 \mu \mathrm{m}$., scabrate, thickness of nexine $0.7+0.13 \mu \mathrm{m}$.

Rhizophora mucronata Lamk. (Rhizophoraceae) (Fig. 2G, H)

Pollen grains tricolporate, isopolar, radially symmetric, amb circular, peritreme, prolate, PA x ED $27.5+0.13 \times 23.7+0.07 \mu \mathrm{m}$. L/B of colpi 15.0 $+0.09 / 2.8+0.05 \mu \mathrm{m}$., ora lalongate, $\mathrm{L} / \mathrm{B}$ of ora $6.5+0.2 / 10.2+0.15$ $\mu \mathrm{m}$., mesocolpium $12.5+0.11 \mu \mathrm{m}$., apocolpium $8.7+0.09 \mu \mathrm{m}$. Thickness of exine $2.5+0.16 \mu \mathrm{m}$., intectate, thickness of sexine $1.8+0.04 \mu \mathrm{m}$., reticulate, thickness of nexine $0.7+0.15 \mu \mathrm{m}$.

Pollen grains viability test of fresh pollen materials was performed using $1 \%$ aceto-orcein solution (Table. 1 ). The pollen grains with dark stain were viable and those unstained or partially stained were non-viable. The result shows more than $90 \%$ pollen viability in the investigated taxa with the highest in R. mucronata (97.66\%) and the lowest in B. sexangula $(90.80 \%)$. A. marina and C. tagal also recorded $97.43 \%$ and $95.18 \%$, respectively.

The percentage high viability of fertile pollen grains (Table 2) in A. marina was highest (92.10\%) in $2 \%$ sucrose solution and least fertility (25\%) was found in $0.2 \%$ sucrose solution. Considering pollen germination, the highest pollen tube length $(226.6 \mathrm{~m}$ ) was found in $2 \%$ sucrose solution and lowest 
Table. 1. Pollen viability test by staining in $1 \%$ aceto-orcein solution.

\begin{tabular}{lll}
\hline \multirow{2}{*}{ Material } & \multicolumn{2}{c}{ Viability Test* } \\
\cline { 2 - 3 } & Total cells & Viable cells \\
\hline Avicennia marina & $7.8 \pm 0.41$ & $7.6 \pm 0.37(97.43 \%)$ \\
Bruguiera sexangula & $9.8 \pm 0.85$ & $8.9 \pm 0.67(90.8 \%)$ \\
Ceriops tagal & $16.6 \pm 1.33$ & $15.8 \pm 1.87(95.18 \%)$ \\
Rhizophora mucronata & $17.1 \pm 1.10$ & $16.7 \pm 1.19(97.66 \%)$ \\
\hline
\end{tabular}

* Average of ten slides, \pm SE

(33.3 $\mathrm{m}$ ) in $1.2 \%$ solution. The percentage of fertile pollen grains of $B$. sexangula was highest $(80 \%)$ in $1.6 \%$ sucrose solution followed by $2 \%$ and $1 \%$ solution. In other sucrose solutions complete sterility was observed. In case of pollen germination, the highest pollen tube length $(191.6 \mathrm{~m})$ was found in $2 \%$ sucrose solution followed by 1 and $1.6 \%$ solution. In C. tagal, the highest percentage of pollen grain fertility was observed at $1.6 \%$ sucrose (88.7\%) followed by 1.2 and $1.0 \%$ of sucrose solution. Maximum pollen tube length was observed in $1.6 \%$ solution $(196 \mathrm{~m})$. Maximum pollen fertility (88.3\%) in R. mucronata was observed in $1 \%$ sucrose solution followed by 1.6 and $1.2 \%$ solution. In other sucrose concentrations, complete pollen sterility was recorded. Considering pollen germination, maximum pollen tube length $(281.6 \mathrm{~m})$ was found in $1 \%$ sucrose solution followed by 1.6 and 1.2 $\%$ of sucrose.

A strong positive correlation between pollen grain fertility and the length of the pollen tube germinated in different concentrations of sucrose is presented in Table 2 . The correlation value ranges from $0.7-0.9$ (with minimum correlation value in $R$. mucronata).

\section{DISCUSSION}

Morphological examinations of pollen grains revealed that all the taxa investigated had tricolporate, prolate or subprolate pollens with surface ornamentation that are reticulate or scabrate. A. marina and R. mucronata 


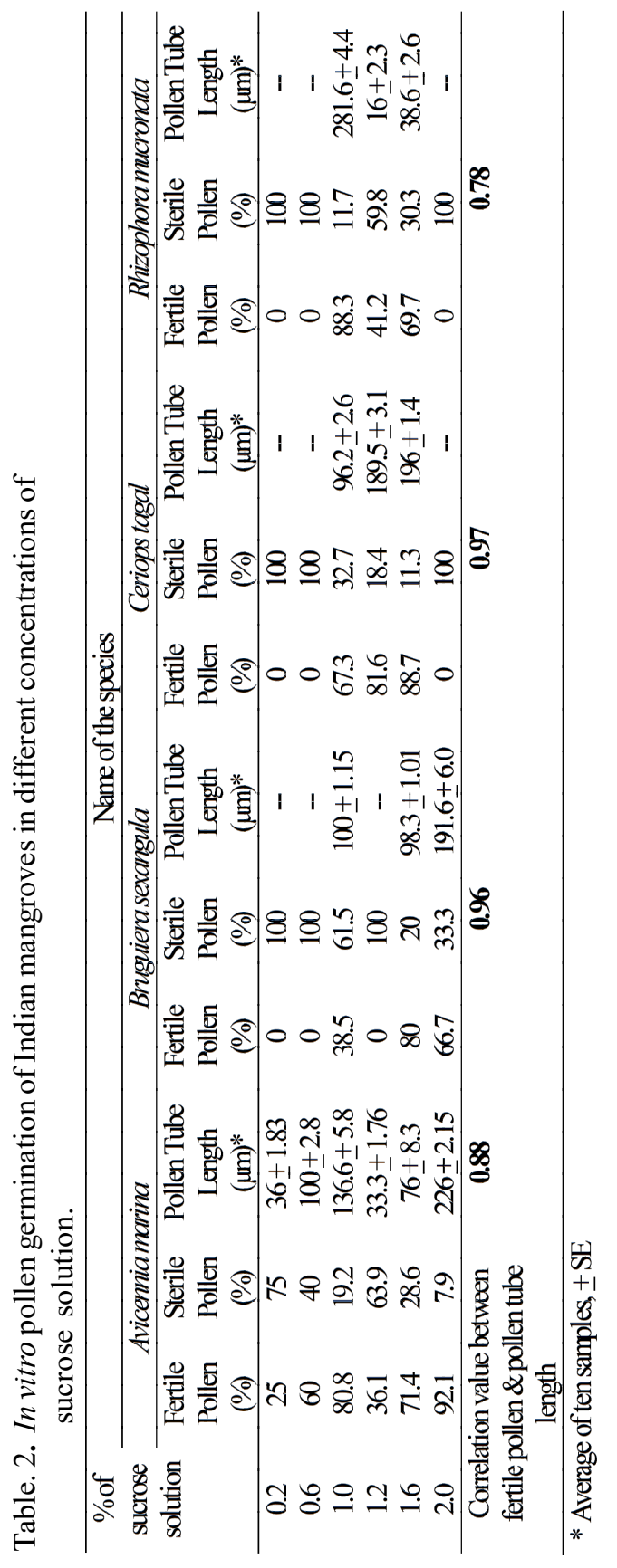


pollens were larger in size than that of the other two taxa (B. sexangula and C. tagal). Pollen grains viability test with $1 \%$ aceto-orcein shows that all the investigated taxa produced more than $90 \%$ viable pollens under in situ condition that ultimately lead to successful participation in pollination mechanism and seed production. Farkas and Orosz-Kovacs (2004) conducted an experiment on pollen grain viability in pear (Pyrus betulifolia) and obtained above $50 \%$ viable pollen grains. He concluded that this percentage is sufficient for successful pollination and enough to attract bees. The present work also was inconformity with this view as all the four species investigated produced a fairly good amount of seeds per year. Bernal et al. (2005) opined that in vitro pollen germination analysis is a suitable method for studying male fertility, and probably a reliable process of estimation for seed production.

In the present work, estimation of pollen tube germination was done in different sucrose concentrations $(0.2-2.0 \%)$. The pollen germination rate and length of pollen tube in $A$. marina and $B$. sexangula were highest in $2.0 \%$ sucrose solution, whereas in $C$. tagal and $R$. mucronata, these two parameters occurred in comparatively low sucrose concentrations ( 1.6 and $1.0 \%$, respectively). The pollen germination results decreased as sucrose concentration increased in the latter two species. So, the required sucrose concentration for optimum pollen germination and pollen tube length varies from species to species. Xu et al. (2004) studied pollen germination of Heptacodium miconioides in eight different culture media and reported that boric acid with NAA or calcium nitrate could promote pollen germination and pollen tube growth. Youmbi et al. (2004) conducted an experiment to determine the optimal condition for in vitro germination and preservation of Canarium schweinfurthii pollen and revealed that the germination percentage increased with increase in sucrose concentration and become inhibited when optimum concentration exceeded. Sharma et al. (2003) studied pollen viability of pomegranate (Punica granatum L.) in $2 \%$ aceto-carmine and $1 \%$ tetrazolium salt solution, and hanging drop method using sucrose solution at various concentrations and reported that the highest pollen germination $(72.05 \%)$ was observed in $12.5 \%$ sucrose added with 10 ppm of boric acid solution. According to Xie et al. (2004), high sucrose content on the medium enhanced germination and pollen tube development in Asian pear. The relation between the rate of pollen grain germination and pollen tube length was evaluated and 
found a strong positive correlation. However, there was no correlation between sucrose concentration and pollen tube lengthwhich is supported by earlier work of Bernal et al. (2005). The viable pollen production and pollen grain germination confirm the suitability of the studied taxa in the habitat since the number of viable pollen in natural habitat indicates successful pollination, that ultimately leading to seed production.

\section{REFERENCES}

BERNAL, C., G. PALOMARES, I. SUSIN. 2005. Establishment of a germination medium for artichoke pollen and its relationship with seed production. Acta-Horticult. 681:291-299.

CARATINI, C., G. THANIKAIMONI, C. TISSOT. 1980. Mangroves of India: Palynological study and recent history of the vegetation. Proc. IV Internatl. Palynol. Conf. 3:49-59.

CLAßEN-BOCKHOFF, R. 2007. Floral Construction and pollination biology in the Lamiaceae. Annals of Botany 100(2):359-360.

DAS, S. 1999.An adaptive feature of some mangroves of Sundarbans, West Bengal. $J$. Plant Biology 42(2): 109 - 116.

DAS, S., and M. GHOSE.1990. Pollen morphology of some mangrove plants of Sundarbans, West Bengal. J. Natl. Bot. Soc. 44:59-75.

FARKAS, A., Z. OROSZ-KOVACS. 2004. Primary and secondary attractants of flowers in pear (Pyrus betulifolia). Acta-Horticult. 636:317-324.

FAEGRI, K., and J. IVERSEN. 1975. J. Text Book of pollen Analysis. Copenhagen, Munksgaard. 3rd.. ed 1975; p. 295.

FOOD AND AGRICULTURAL ORGANIZATION (FAO). 2003. New global mangrove estimate.Available from: http://www.fao.org/documents/show_cdr.asp?url_file=/ docrep/007/j1533e/j1533e52.htm. Accessed 1 October 2006.

MUCCIFORA, S., L. M. BELLANI, and P. GORI. 2003. Ultrastructure, viability and in vitro germination of the tricellular Sambuscus nigra L. pollen. Internatl. J. Plant Sci. 2003; 164 (6):855-860.

NANDY (DATTA), P., S. DAS, M. GHOSE, and R. SPOONER-HART. 2007. Effects of salinity on photosynthesis, leaf anatomy, ion accumulation and photosynthetic nitrogen use efficiency in five Indian mangroves. Wetl. Ecol. Manage.15:347357. 
PEARSON, H. M., P. M. HARNEY. 1984. Pollen viability in rosa. Hort. Science (5):710-711.

PRAFITT DE GANESHAN, S. 1989. Comparison of procedures for estimating viability of Prunus pollen. Hort. Science 24 (2):354-356.

SANYAL, P. 1996. Sundarbans: The largest mangrove diversity on globe. In: Willium Roxburgh Memorial Seminar on Sundarban Mangals, Calcutta. 1996; 11-26.

SHARMA, N., and H. S. BIST. 2003. Studies on pollen characters and pollination behaviour of pomegranate ( Punica granatum L.) cultivars in mid-hills of Himachal Pradesh. Haryana. J. Hort. Sciences 32(1/2):11-14.

SHENXI XIE, XIANSHI LUO, YUECHANG WU, LOVATT CJ. Pollen viability of Asian pear and effect of PGR, B and sucrose on germination and pollen tube development. J. Fruit Sci. 21(4): 289-294.

THANIKAIMONI, G. 1987. Mangrove palynology. UNDP/UNSCORegional Project on Training and Research on mangrove ecosystem. Institut Francais de Pondichery, India.; $100 \mathrm{p}$.

TYAGI, A. P. 2002. Cytogenetics and reproductive biology of mangroves of Rhizophoraceae. Aust. J. Bot. 50(5):601-605.

WERNER, D. J., and S. CHANG. 1981. Stain testing viability in stored peach pollen. Hort. Science 16 (4):522-523.

WAISEL, Y. 1972. Biology of Halophytes. Academic Press, NY. 395 p.

XIE-SHEN XI, LUO-XIAN SHI, WU-YUE CHANG, LOVATT, CJ. 2004. Pollen viability of Asian pear and effect of PGR, B and sucrose on germination and pollen tube development. J. Fruit Science 21(4):289-294.

XU DONG QING, CHU LI MIN, CAI JIE JIE. 2004. Study of pollen germination of Heptacodium miconioides. J. Zhejiang Forestry Science and Technol. 24 (2):57. 